\title{
Stability of $\mathrm{N}$-glycosidic bond of (5'S)-8,5'-cyclo-2'- deoxyguanosine
}

\author{
Rajat S. Das, Milinda Samaraweera, Martha Morton ${ }^{\dagger}$, José A. Gascón, and Ashis K. Basu* \\ Department of Chemistry, University of Connecticut, Storrs, CT 06269
}

\section{Abstract}

$8,5^{\prime}$-Cyclopurine deoxynucleosides are unique tandem lesions containing an additional covalent bond between the base and the sugar. These mutagenic and genotoxic lesions are repaired only by nucleotide excision repair. The $\mathrm{N}$-glycosidic (or $\mathrm{Cl}^{\prime}$-N9) bond of $2^{\prime}$-deoxyguanosine (dG) derivatives is usually susceptible to acid hydrolysis, but even after cleavage of this bond of the cyclopurine lesions, the base would remain attached to the sugar. Here, the stability of the $N$ glycosidic bond and the products formed by formic acid hydrolysis of $\left(5^{\prime} S\right)-8,5^{\prime}$-cyclo- $2^{\prime}$ deoxyguanosine ( $S$-cdG) were investigated. For comparison, the stability of the $N$-glycosidic bond of $8,5^{\prime}$-cyclo-2' $2^{\prime} 5^{\prime}$-dideoxyguanosine (ddcdG), 8-methyl-2' -deoxyguanosine (8-Me-dG), 7,8dihydro-8-oxo- $2^{\prime}$-deoxyguanosine (8-Oxo-dG), and dG was also studied. In various acid conditions, $S$-cdG and ddcdG exhibited similar stability to hydrolysis. Likewise, 8-Me-dG and dG showed comparable stability, but the half lives of the cyclic dG lesions were at least 5-fold higher than $\mathrm{dG}$ or 8-Me-dG. NMR studies were carried out to investigate the products formed after the cleavage of the $\mathrm{C} 1^{\prime}$-N9 bond. 2-Deoxyribose generated $\alpha$ and $\beta$ anomers of deoxyribopyranose and deoxyribopyranose oligomers following acid treatment. $S$-cdG gave a and $\beta$ deoxyribopyranose linked guanine as the major products, but $\alpha$ and $\beta$ anomers of deoxyribofuranose linked guanine and other products were also detected. The $N$-glycosidic bond of 8-Oxo-dG was found exceptionally stable in acid. Computational studies determined that both the protonation of the N7 atom and the rate constant in the bond breaking step control the overall kinetics of hydrolysis, but both varied for the molecules studied indicating a delicate balance between the two steps. Nevertheless, the computational approach successfully predicted the trend observed experimentally. For 8-Oxo-dG, the low pKa of $O^{8}$ and N3 prevented appreciable protonation, making the free energy for $\mathrm{N}$-glycosidic bond cleavage in the subsequent step very high.

\section{Introduction}

The tandem DNA lesions, $8,5^{\prime}$-cyclopurine $2^{\prime}$-deoxynucleosides (cPDNs), formed by ionizing radiation and other processes that generate reactive oxygen species, are unique in that they contain damage to both the purine base and the $2^{\prime}$-deoxyribose sugar moiety. ${ }^{1}$ These lesions exist as $5^{\prime} R$ and $5^{\prime} S$ diastereomers and have been detected in vitro and in vivo in DNA derived from many different cells and organisms. ${ }^{2-4}$ Although these lesions have been discovered in the 1960s, ${ }^{5}$ they received more attention in recent years prompted by two reports in 2000 showing that in mammalian cells $8,5^{\prime}$-cyclo-2' deoxyadenosine (cdA) diastereomers are repaired by nucleotide excision repair (NER), and not by base excision

\footnotetext{
*Address correspondence to: Ashis K. Basu, Department of Chemistry, University of Connecticut, Storrs, CT. Tel. 860-486-3965; Fax 860-486-2981; ashis.basu@uconn.edu.

†Current address: Department of Chemistry, University of Nebraska, Lincoln, NE

SUPPORTING INFORMATION AVAILABLE

Additional NMR data (four tables and two figures) are available free of charge via the Internet at http://pubs.acs.org.
} 
repair. ${ }^{6,7}$ However, a study in 2010 provided evidence for involvement of the DNA repair enzyme NEIL1 in NER of $R$-cdA and $S$-cdA in mice, although the mechanism remains unclear. ${ }^{8} R$-cdA is more efficiently repaired by NER than $S$-cdA, indicating that the stereochemistry of these lesions are important. ${ }^{6}$ The cPDNs have been claimed to play a role in neurologic diseases in certain Xeroderma Pigmentosum patients with defects in NER. ${ }^{9}$ It was also shown that $S$-cdA accumulates in vivo in genomic DNA of $\mathrm{csb}^{-/}$mice, suggesting that this lesion may accumulate in Cockayne syndrome patients. ${ }^{10} S$-cdA has been reported to be a strong block of gene expression in Chinese hamster ovary and human cells. ${ }^{7}$ It prevents the binding of TATA binding protein and strongly reduces transcription in vivo. ${ }^{11}$ Both $R$-cdA and $S$-cdA block the elongation of a primer in vitro by mammalian DNA polymerase $\delta$ and T7 DNA polymerase, ${ }^{6}$ whereas mammalian DNA polymerase $\eta$ can bypass $R$-cdA but not $S$-cdA. ${ }^{12}$ Recently, $\left(5^{\prime} S\right)-8,5^{\prime}$-cyclo- $2^{\prime}$-deoxyguanosine ( $S$-cdG) was shown to be significantly mutagenic in Escherichia coli inducing primarily $S$-cdG $\rightarrow$ A mutations. ${ }^{13,14}$ The structures of oligodeoxynucleotide duplexes containing a site-specific $S$ cdG lesion placed opposite $\mathrm{dC}, \mathrm{dT}$, or $\mathrm{dA}$ in the complementary strand were obtained by a combination of solution NMR spectroscopy and molecular dynamics calculations. ${ }^{15,16}$ These studies showed that the $S$-cdG deoxyribose is in the $\mathrm{O}^{\prime}$-exo (west) pseudorotation in each pair. The Watson-Crick base pairing was conserved in the $S$-cdG・dC pair, whereas the $S$-cdG $\bullet$ dT pair adopts a wobble pairing. In contrast, no hydrogen bonding was observed for the $S$-cdG・dA pair, which differs in conformation from the dG・dA mismatch pair.

For many DNA lesions, structural changes of the purine or pyrimidine residue accompany destabilization of the $\mathrm{N}$-glycosidic bond. The N7 position of guanine is the most nucleophilic site among the DNA bases, and $2^{\prime}$-deoxyguanosine $(\mathrm{dG})$ is particularly susceptible to acid-catalyzed depurination. ${ }^{17}$ The $\mathrm{p} K \mathrm{~K}$ of N7-protonated dG in DNA has been estimated to be between 2.5 and 3.0. ${ }^{18}$ In low $\mathrm{pH}$, therefore, $\mathrm{S}_{\mathrm{N}} 1$ type hydrolysis occurs via protonation at $\mathrm{N} 7$ position of $\mathrm{dG}$ followed by cleavage of the $\mathrm{C1}^{\prime}$-N9 bond. Theoretical studies show that for $\mathrm{dG}$ at neutral $\mathrm{pH}$, the hydrolysis consists of two steps, but the Gibbs free energy barrier for the first step is very high. ${ }^{19}$ By contrast, the N7-protonated $\mathrm{dG}$ follows a different two-step mechanism with a much lower Gibbs free energy barrier for the first step, ${ }^{19,20}$ classified as $D_{N}+A_{N}$ reaction (or $D_{N} * A_{N}$ where “*” indicates that a short-lived oxacarbenium ion is formed). ${ }^{21}$ Because of the $\mathrm{C} 8-\mathrm{C} 55^{\prime}$ covalent bond in cPDNs, it is anticipated that the purine and the deoxyribose will remain attached even after the cleavage of the $\mathrm{C} 1^{\prime}$-N9 bond. The hydrolysis of the $\mathrm{N}$-glycosidic bond of $S$-cdA has been shown to be $\sim 40$-fold more stable than dA in acid. ${ }^{22}$ But the chemical stability of the $N$ glycosidic bond of either $R$ - or $S$-cdG is not known. Herein, we have investigated the stability of the $N$-glycosidic bond of $S$-cdG in comparison to dG and several analogs of $S$ $\mathrm{cdG}$, including a cyclic analog (ddcdG), an acyclic analog (8-Me-dG), and 8-Oxo-dG. The products formed following hydrolysis of the $\mathrm{C} 1^{\prime}$-N9 bond were also investigated.

\section{Materials and Methods}

$S$-cdG and ddcdG were synthesized and characterized as reported. ${ }^{15,23} 8$-Me-dG was prepared according to Kohda et al. ${ }^{24}$ 8-Oxo-dG and dG were purchased from Berry and associates (Dexter, MI). Bulk solvents were purchased either from Sigma Aldrich (St. Louis, MO) or Fisher Scientific (Clifton, NJ). Deuterated solvents were purchased from Cambridge Isotope Laboratories (Andover, MA). Water used for this study was obtained from a Barnstead Nanopure System (Thermo Scientific, Dubuque, IA). All reagents used were of highest purity available. The silica gel used for flash chromatography $(40-63 \mu \mathrm{m})$ and gravitational column $(63-200 \mu \mathrm{m})$ were purchased from Sorbent Technology (Norcross, GA). NMR data was analyzed using TOPSPIN software and referenced against residual solvent peak. Mass spectral analyses were performed on a Qstar Elite mass spectrometer 
(Applied Biosystems, Carlsbad, CA) using collision-induced dissociation to detect the fragmentation pattern.

\section{HPLC analysis}

HPLC analyses were performed on a reversed phase column (Synergi 4 Wm Hydro-RP $80 \AA$ LC Column $250 \times 4.6 \mathrm{~mm}$, Phenomenex, Torrance, CA) using a Waters 1525 HPLC system (Waters, Milford, MA) equipped with a diode-array detector (model 2996). A gradient elution program with $100 \%$ water to $15 \%$ acetonitrile with a flow rate of $1 \mathrm{~mL} / \mathrm{min}$ in 20 min was used.

\section{Formic acid hydrolysis}

The acid hydrolysis was monitored either at regular intervals after treatment with a specific acid concentration or the reaction time was kept constant but the acid concentration was varied. For the time-course experiments, $\sim 3 \mathrm{nmol}$ of samples were incubated in $10 \%(\mathrm{v} / \mathrm{v})$ formic acid at $37^{\circ} \mathrm{C}$ for various times and an aliquot was neutralized with ice cold ammonia solution. To determine the effect of increasing acid concentration on $\mathrm{N}$-glycosidic bond stability, $\sim 3 \mathrm{nmol}$ of samples were incubated in various concentrations of formic acid for 4 $\mathrm{h}$, and the reaction mixtures were neutralized with ice-cold ammonia. After drying, a known amount $(1 \mathrm{nmol})$ of adenosine was added as internal standard to each sample and total volume was made up to $100 \mu \mathrm{L}$ by adding water. The samples were injected on to a $\mathrm{C} 18$ analytical column. Amount of hydrolyzed product formed or nucleoside remaining were measured by integrating the area under peak at $254 \mathrm{~nm}$.

\section{NMR analysis}

For dG and 8-Me-dG, NMR kinetic experiments were performed on a Bruker Avance III $400 \mathrm{MHz}$ NMR spectrometer in 10\% DMSO-d6, 20\% DCOOD and 70\% $\mathrm{D}_{2} \mathrm{O}$. For ddcdG, the data including ${ }^{13} \mathrm{C}$ data were obtained through direct detection methods. The experiments to determine the acid decomposition products were run on a Bruker Avance I $400 \mathrm{MHz}$ NMR spectrometer. Since the solubility of $S$-cdG in the above solvent mixture was poor, the spectra were recorded on a Varian Inova $600 \mathrm{MHz}$ NMR spectrometer with a ${ }^{1} \mathrm{H}$ detect cold probe, and the ${ }^{13} \mathrm{C}$ data were acquired using indirect detection from the ${ }^{13} \mathrm{C}$ HSQC and HMBC. For a typical hydrolysis experiment, approximately $30 \mathrm{mM}$ solution of the substrate was prepared in $600 \mu \mathrm{L} 20 \%$ DCOOD, $70 \% \mathrm{D}_{2} \mathrm{O}$, and 10\% D6-DMSO. This solution was immediately introduced into the spectrometer for kinetic studies and the probe temperature was maintained at $37^{\circ} \mathrm{C}$. Due to very poor solubility of $S$-cdG, the sample was prepared in a similar way and the turbid solution was centrifuged at $14000 \mathrm{rpm}$ for 2 minutes. The clear supernatant was used for the kinetic studies. The ratio of the products formed from 2-deoxyribose was determined from the integrals of the two deoxyribopyranose and the oligomer peaks from the $\mathrm{C} 1^{\prime}$ protons between 4.5 and $5.5 \mathrm{ppm}$ and from the $\mathrm{C} 2^{\prime}$ protons between 1.4 and $2.5 \mathrm{ppm}$. Similarly, for ddcdG and $S$-cdG the integrals of the $\mathrm{C}^{\prime}{ }^{\prime}$ protons between 1.5 and $2.7 \mathrm{ppm}$ were used.

\section{Computational methods}

Geometry optimization of reactant and transition states were carried out with the quantum chemistry package Gaussian $09,{ }^{25}$ using Density Functional Theory (DFT) with the B3LYP 26,27 functional and basis set 6-31++G(d,p). Solvent effects were taken into account using the Polarized Continuum Model (PCM $)^{28}$ with water as an implicit solvent. Transition state structures were located using the Synchronous Transit-Guided Quasi-Newton method. ${ }^{29}$ Harmonic vibrational frequencies were calculated for the stationary points. This frequency analysis was also used to calculate Gibbs free energies at $310.0 \mathrm{~K}$, needed to determine activation free energy barriers and rate constants. 
Protonation of the N7 atom in the nucleoside (Nu) induces the cleavage of the $\mathrm{N}$-glycosidic bond followed by nucleophilic substitution of the formed oxacarbenium ion by water, leading to the corresponding products (Scheme 1).

The nucleosides 8-Me-dG, dG, ddcdG and $S$-cdG involve a rapid pre-equilibrium between protonated and un-protonated states of $\mathrm{N} 7$ atom before the slow rate determining step $\left(k_{2}\right)$, thus leading to an overall rate constant $\left(k_{\mathrm{obs}}\right)$,

$$
k_{\mathrm{obs}}=\frac{k_{2}}{10^{-\mathrm{pKa}}}\left[\mathrm{H}^{+}\right]=\frac{k_{2}}{K_{\mathrm{a}}}\left[\mathrm{H}^{+}\right]
$$

where $k_{2}$ is the rate constant for the cleavage of the $\mathrm{N}$-glycosidic bond (rate determining step), calculated according to the Eyring equation:

$$
k_{2}=\frac{k_{B} T}{h} e^{-\frac{\Delta^{\dagger} G}{R T}}
$$

where $\Delta^{\dagger} G$ is the free energy of activation, $k_{B} T$ is the thermal energy $(T=310.15 \mathrm{~K}), R$ is the gas constant, and $h$ the Planck constant. The pKa at the N7 position was calculated with the pKa module in the quantum chemistry package Jaguar (Schrödinger, Inc).$^{30}$ The half-life was computed as $t_{1 / 2}=0.693 / k_{\text {obs }}$. Equation 1 and 2 imply that, at constant $k_{2}$, the lower the $\mathrm{pKa}$, the more stable is the bond (larger $t_{1 / 2}$ ). Similarly, at constant $\mathrm{pKa}$, the lower $k_{2}$, the more stable is the bond.

\section{Results}

\section{$\mathrm{N}$-Glycosidic bond cleavage of S-cdG}

To determine the identity of the products formed via cleavage of the $\mathrm{N}$-glycosidic bond of $S$ cdG, we treated it with $10 \%$ formic acid at $37{ }^{\circ} \mathrm{C}$ and analyzed the products by reversephase HPLC. Figure 1 shows the HPLC chromatogram after $7 \mathrm{~h}$ treatment, in which part of $S$-cdG (the 13.7 min peak) was converted to two other products, the first one eluting at 10.8 min followed by a small broad peak eluting at $11.7 \mathrm{~min}$. We referred to the first $10.8 \mathrm{~min}$ peak as hydrolyzed cdG (hcdG). Mass spectral analysis of hcdG showed a mass ion of 284.1 $\mathrm{Da}$, representing protonated molecular ion $\left(\mathrm{MH}^{+}\right)$of a $\mathrm{H}_{2} \mathrm{O}(18 \mathrm{Da})$ addition product of $S$ $\mathrm{cdG}(\mathrm{m} / \mathrm{z} 266)$, as well as the sodium adduct ion $\left(\mathrm{MNa}^{+}\right)$at $306 \mathrm{Da}$ (Figure 2). Mass fragmentation of hcdG was analyzed by collision-induced dissociation (CID MS/MS), which exhibited ions at $\mathrm{m} / \mathrm{z} 266,248$, and 230 owing to three consecutive water elimination, plus 194 and 180 (Figure 2 inset). Since the mass of $S$-cdG is 266 , the ion at $m / z 180$ originated from the base moiety plus the $5^{\prime}-\mathrm{CHOH}$ part of the sugar. The ion at $m / z 194$ is likely to be a fragment ion composed in addition to the base and $5^{\prime}-\mathrm{CHOH}$, the $4^{\prime}-\mathrm{CH}$ (plus an $\mathrm{H}$ ). Taken together, these data suggest that hcdG is the hydrolysis product of $S$-cdG. We considered it likely that the cleavage of $\mathrm{C1}^{\prime}$-N9 bond followed by addition of a water molecule generates hcdG, which is consistent with a stepwise formation of oxacarbenium ion intermediate that undergoes nucleophilic attack by the water molecule in an $\mathrm{S}_{\mathrm{N}} 1$ mechanism $\left(D_{N} * A_{N}\right)(S c h e m e 2)$. The relative amount of the second broad peak at 11.7 min varied from one injection to another, and, upon reinjection, it gave $>95 \%$ of the first peak, hcdG, suggesting that it is one of the unstable intermediates.

When $\mathrm{dG}$ was incubated with acid under similar conditions, it was $77 \%$ converted to guanine in $2 \mathrm{~h}$ (when only $18 \% S$-cdG was hydrolyzed), suggesting that $S$-cdG was significantly more resistant to acid hydrolysis. In order to further investigate the $N$ glycosidic bond stability of $S$-cdG, we compared the kinetics of cleavage of this cyclopurine 
nucleoside with $8,5^{\prime}$-cyclo- $2^{\prime}, 5^{\prime}$-dideoxyguanosine (ddcdG), a cyclic analog, and 8methyl-2' -deoxyguanosine (8-Me-dG), an acyclic analog of cdG (Chart 1). We selected these two compounds because, like $S$-cdG, each compound contains a sp ${ }^{3}$-hybridized carbon attached to guanine-C8, but only ddcdG contains an additional ring like $S$-cdG. We also analyzed the $\mathrm{N}$-glycosidic bond stability of dG and 8-Oxo-dG, the latter containing an oxygen substitution at guanine-C8. In one set of experiments, we monitored the $\mathrm{N}$ glycosidic bond cleavage at $37{ }^{\circ} \mathrm{C}$ in $10 \%$ formic acid by reverse-phase HPLC. Figure 3 shows the kinetics of hydrolysis of $S$-cdG, including the time course of generation of hcdG peak in the inset. The hydrolysis was also monitored by ${ }^{1} \mathrm{H}-\mathrm{NMR}$ (Figure 4), except we used $20 \%$ DCOOD, $10 \%$ DMSO- $d_{6}$, and $70 \% \mathrm{D}_{2} \mathrm{O}$ due to poor solubility of $S$-cdG in $10 \%$ deuterated formic acid. The kinetics of hydrolysis was followed by integrating the $\mathrm{H}-\mathrm{1}^{\prime}$ peak area at $6.52 \mathrm{ppm}$, since it became smaller as more substrate was hydrolyzed. When similar experiments were performed with $\mathrm{dG}$, ddcdG, and 8-Me-dG, it was apparent that the hydrolysis of $S$-cdG was similar to ddedG, whereas dG hydrolysis was comparable to 8-MedG (Figure 5). As shown in Figure 5A, in which reverse-phase HPLC monitoring was employed, and in Figure 5B, which utilized NMR monitoring of the intensity of $\mathrm{H}-1^{\prime}$ proton signal, the kinetics of hydrolysis of the four compounds followed an analogous trend, despite the differences in acid conditions. The half-lives $\left(t_{1 / 2}\right)$ of the four compounds show a similar pattern (Figure 5C), also indicating that $S$-cdG hydrolysis was more than 5 times slower than dG. We also determined that 8-Oxo-dG was much more resistant to hydrolysis than the four other nucleosides evaluated here, in that $>99 \%$ of 8-Oxo-dG was recovered after incubation in $10 \%$ formic acid for 7 days at $37{ }^{\circ} \mathrm{C}$ (data not shown). In another set of experiments, we varied the formic acid concentrations but analyzed the products in each case after a $4 \mathrm{~h}$ time interval (Figure 6). The concentration of formic acid needed to obtain $50 \%$ depurination of dG was $1.7 \%$ compared to $19 \%$ for $\mathrm{N}$-glycosidic bond cleavage of $S$ cdG, whereas the same for ddcdG and $8-\mathrm{Me}-\mathrm{dG}$ were $18.9 \%$ and $0.9 \%$, respectively. Again, the acid concentration needed to cause $50 \%$ hydrolysis of $S$-cdG was similar to ddcdG, whereas the same for 8-Me-dG and dG was comparable. But compared to dG or 8-Me-dG, a ten-fold acid higher concentration was needed to hydrolyze $50 \% S$-cdG or ddcdG. Based on these three sets of experiments, we conclude that the $N$-glycosidic bond of $S$-cdG is 5-10times more stable to acid hydrolysis than that of dG.

\section{NMR analysis of $\mathbf{N}$-glycosidic bond cleavage of $\mathbf{S}$-cdG}

In order to understand the products formed by acid hydrolysis of $\mathrm{dG}$ and $\mathrm{dG}$ derivatives, we followed the reaction of 2-deoxyribose in deuterated formic acid. After $24 \mathrm{~h}$ in $20 \%$ DCOOD, $10 \%$ DMSO- $d_{6}$ and $70 \% \mathrm{D}_{2} \mathrm{O}$ at $37{ }^{\circ} \mathrm{C}$, both ${ }^{13} \mathrm{C}$ - and ${ }^{1} \mathrm{H}-\mathrm{NMR}$ indicated that 2deoxyribose no longer had any detectable signal of the deoxyribofuranose form. As shown in Figure 7 (Panel A \& B), ${ }^{1} \mathrm{H}-\mathrm{NMR}$ indicated that four major products were generated from 2-deoxyribose, which included a deoxyribopyranose (35\%), $\beta$ deoxyribopyranose (30\%), and two deoxyribopyranose oligomers (15\% each) (Scheme 3 ). There also were other unidentified minor products. Additional details of the spectral data are provided in Table S1 (Supporting Information). Formic acid hydrolysis of dG and 8-Me-dG under similar conditions showed a nearly identical product profile, in addition to the heterocyclic base (data not shown). It is noteworthy that when DCOOD was replaced with DCl, extensive polymerization and degradation of the sugar took place, making the product profile difficult to analyze (data not shown).

The ${ }^{13} \mathrm{C}$ chemical shift data of ddcdG in neutral and acidic conditions are shown in Table S2 in the Supporting Information. The upfield shift of $-5.4 \mathrm{ppm}$ at $\mathrm{C} 5$ and the downfield shift of $4.9 \mathrm{ppm}$ at $\mathrm{C} 8$ on acidification with $10 \%$ deuterated formic acid suggest protonation of $\mathrm{N} 7,{ }^{31,32}$ consistent with the general mechanism of $\mathrm{N}$-glycosidic bond cleavage of dG derivatives as postulated in Scheme 2. 
The ${ }^{1} \mathrm{H}$ NMR spectra of $S$-cdG in DMSO- $d_{6}$ is shown in Figure $S 1$ in the Supporting Information. For $S$-cdG in acid, we could identify the guanine linked $a$ and $\beta$ deoxyribopyranose by $\mathrm{Cl}^{\prime}$ chemical shift and $\mathrm{H}^{\prime}$ coupling constants (Figure 8 and Table $\mathrm{S} 3$, Supporting Information). The guanine linked deoxyribofuranoses were identified by $\mathrm{C}{ }^{\prime}$ and $\mathrm{C} 2^{\prime}$ chemical shifts. No oligomers were formed, presumably because of the steric effect of the attached guanine. But there was an unidentified product. We hypothesize this product to be a septanose derivative, formed via attack of N7 or N9 of guanine to the aldehyde carbon of the ring-opened deoxyribose (Scheme 4). A septanose derivative was also detected in the reaction mixture of formic acid-hydrolyzed ddcdG, which cannot form the deoxyribopyranoses (Figure S2, Supporting Information). But definitive characterization of these compounds must await further investigation. The hydrolysis of $81 \% S$-cdG generated the deoxyribopyranose derivatives as the major products (46\%) with a small fraction (12\%) of deoxyribofuranose derivatives and $23 \%$ other products, which included the suspected guanine linked septanose (Figure 8; Scheme 4).

It is interesting to note that HPLC analyses of $S$-cdG hydrolysis gave one major peak, in addition to the unhydrolyzed starting material, as shown in Figure 1. Since the molecular mass of the various products shown in Scheme 4 is the same, we suspect that the $10.8 \mathrm{~min}$ peak in Figure 1 included all these different hcdG isomers. Our attempts to separate these molecules by HPLC using a variety of columns and conditions were unsuccessful, which may suggest that these isomeric deoxypyranoses, deoxyfuranoses, and other products remain in equilibrium.

\section{Insights from the computational study}

Computational studies are often valuable complement to experimental observations. Accordingly, using a theoretical approach, we explored the effects of protonation of $S$-cdG in comparison to $\mathrm{dG}$ and $\mathrm{dG}$ derivatives investigated here. Our goal was to compute the $\mathrm{pKa}$ values of the protonated nucleosides as well as the activation energies and rate constants of the process represented in Scheme 1, so that their half-lives can be determined. Optimized geometries for reactants and their transition states were in agreement with structures previously reported. ${ }^{19,33,34}$ In particular, in agreement with the literature data, ${ }^{35,36}$ the minimum energy structure of $\mathrm{dG}$ and 8-Oxo-dG was in the anti conformation, whereas that of 8-Me-dG was measured in the syn conformation (Figure 9). Evidently, $S$-cdG and ddcdG are locked in the anti orientation (Figure 9). The pKa of the protonated $S$-cdG was found lower than the other three nucleosides (Table 1). The computational prediction of the overall rate constants for the $\mathrm{N}$-glycosidic bond cleavage (Table 1) allowed us to determine the factors for acid-catalyzed bond stability across all the $\mathrm{dG}$ derivatives studied. The experimentally observed order of stability and the ratio of half-lives of the nucleosides, using $\mathrm{dG}$ as a reference, showed a very good qualitative agreement with the calculated values (Table $2 \&$ Figure 5C). According to Eq. 2, both the protonation of the N7 atom and the rate constant in the bond breaking step control the overall kinetics. Lower pKa implies a lower number of protonated $\mathrm{N} 7$ molecules, thus diminishing the probability for the $\mathrm{N}$ glycosidic bond to cleave. On the other hand, a higher activation barrier in this last process will also disfavor cleavage of the bond. Considering all these contributions in Table 1, it is clear that neither pKa nor $k_{2}$ remain constant for the molecules studied. Thus, there appears to be a delicate balance between the two steps. Let us consider, for instance, the marked difference between the pKa at the N7 position for $S$-cdG (2.7) and ddcdG (3.7). This difference alone affects the overall rate constant by an order of magnitude. Thus, in this case, it is the pKa that is mostly the determining factor, although a higher $k_{2}$ of $S$-cdG relative to ddcdG partly counterbalanced its low $\mathrm{pKa}$. The origin of the more acidic proton in $S$-cdG is due to the unfavorable dipole-dipole interaction between the $5^{\prime}-\mathrm{OH}$ and the N7$\mathrm{H}$ atom. When $\mathrm{dG}$ and 8-Me-dG, with almost identical stability, are compared, there appears 
to be a compensation of effects of almost equal magnitude. The slightly lower pKa in $\mathrm{dG}$ tends to make the reaction slower by a factor of 2 , while the actual water-mediated cleavage is faster by roughly a factor of 2.5 . Finally, in the case of $8-\mathrm{Oxo}-\mathrm{dG}$, stability is almost entirely determined by its inability to get protonated. Indeed, calculation of the $\mathrm{pKa}$ at the $O^{8}$ position gives a negative value (not reported in Table 1 ). In this case, protonation can actually occur at the alternative N3 position. However, previously reported pKa value at N3 is also very small. ${ }^{37}$ Thus, significant protonation cannot occur in weak acid conditions, making the free energy for cleavage in the next step very high. This result is consistent with 8-Oxo-dG having the maximum stability found experimentally relative to all other nucleosides studied in this work. Thus, we infer that the high stability of 8-Oxo-dG is largely dominated by the inability of the base to be protonated, and not by the strength of the $N$-glycosidic bond.

Another relevant question is about the intrinsic effect of the cyclic structure of $S$-cdG. To answer this question, it is appropriate to select molecules that have a hydroxyl group at the $5^{\prime}$ position (i.e. $S$-cdG and dG). We proceeded by breaking the $\mathrm{C} 5^{\prime}$-C 8 bond in $S$-cdG and capping the two ends with hydrogen atoms. We carried out this by only permitting rotation of the $\mathrm{CHOH}$ group, while maintaining the $\mathrm{C} 5^{\prime}-\mathrm{C} 8$ distance. This allowed us to estimate the effect of the cyclic form alone. As a result of this bond breaking, the pKa changed from 2.7 to 3.1 , which is very close to the $\mathrm{pKa}$ value of the fully relaxed acyclic compound, $\mathrm{dG}$ (Table 1). This implies that the $\mathrm{C} 5^{\prime}-\mathrm{C} 8$ bond is a necessary condition to make protonated N7 more acidic in $S$-cdG than in dG.

\section{Discussion}

$8,5^{\prime}$-Cyclopurine $2^{\prime}$-deoxynucleosides are biologically important DNA damages. Learning the chemical features of these molecules is critical for analyzing their biological effects. The objective of this investigation on the chemical stability of the $N$-glycosidic bond of $S$-cdG was to provide a better understanding of this lesion. Using different acid conditions, we established that $S$-cdG and ddcdG were much more stable to acid than dG or 8-Me-dG. However, of the five compounds examined, 8-Oxo-dG was most resistant to acid hydrolysis.

\section{Role of the six-membered ring and the sugar pucker of S-cdG}

For nonenzymatic $\mathrm{N}$-glycosidic bond cleavage, conformation changes in the sugar ring to promote favorable orbital interactions have been suggested to play a role. ${ }^{38}$ Significantly higher $\mathrm{N}$-glycosidic bond stability of $S$-cdG and ddcdG compared to dG and 8-Me-dG implies that the new six-membered bicyclic ring structure provides enhanced stability, which is consistent with an earlier investigation that reported $S$-cdA to be $\sim 40$-fold more stable to acid than dA. ${ }^{22}$ However, the computational studies indicate that such generalizations may not be valid and the changes in each step of the pathway should be examined carefully as it is altered by the change in structure and conformation of the molecule. Two recent NMR investigations of $S$-cdG in DNA opposite three different partner bases revealed that in each case $S$-cdG deoxyribose shifts to the $\mathrm{O}^{\prime}$-exo ("West") pseudorotation, which is likely maintained in the $S$-cdG nucleoside, as was reported for the $S$-cA riboside. ${ }^{39}$ The NMR studies ${ }^{15,16}$ showed that the six-membered ring C8-N9-C1' $\mathrm{O} 4{ }^{\prime}-\mathrm{C} 4{ }^{\prime}-\mathrm{C} 5^{\prime}$ adopts a half-chair conformation with the $\mathrm{O} 4^{\prime}$ and $\mathrm{C}^{\prime}$ puckered. The $\mathrm{O} 4{ }^{\prime}-$ exo ("West") is considered an unstable conformer, owing to the axial orientation of the bulkier substituents. In this conformation, the lone pair of $\mathrm{O}^{\prime}$ of the sugar seems suitably aligned with the $\mathrm{C1}^{\prime}$-N9 bond, which would allow the oxygen to stabilize the developing positive charge on $\mathrm{Cl}^{\prime}$ during the bond breaking step. Therefore, a faster hydrolysis is expected, although the magnitude of this effect may be small. ${ }^{40}$ In contrast, increased stability of the N9-C1' bond for $S$-cdG was experimentally observed (Table 2). The computational study indicated that the ring formation in $S$-cdG results in unfavorable dipole- 
dipole interaction between the $5^{\prime}-\mathrm{OH}$ and the $\mathrm{N} 7-\mathrm{H}$ atom. This interaction gives rise to increased acidity of the proton at N7 (Table 1), thereby enhancing the acid stability of the N9-C1' bond. It is tempting to attribute this stability to formation of the new six-membered bicyclic ring system, since both $S$-cdG and ddcdG exhibit comparable stability to hydrolysis. But the mechanism is more complex, because N7-H of ddcdG is less acidic than any nucleoside examined in this study, except a much lower rate constant for step $2\left(k_{2}\right)$ in ddcdG hydrolysis relative to $S$-cdG (and others) counterbalanced its high pKa.

\section{Mechanistic considerations and the acid hydrolysis products}

The ${ }^{13} \mathrm{C}$ chemical shift data in neutral and acidic conditions were consistent with the general mechanism of $\mathrm{N}$-glycosidic bond cleavage of dG derivatives as postulated in Scheme 2. It is well-established for more than forty years that protonation gives rise to substantial acceleration to depurination of $\mathrm{dG},{ }^{41}$ and theoretical studies show that the transition state energy is lowered by $\sim 10 \mathrm{kcal} \mathrm{mol}^{-1.42}$ In the $\mathrm{D}_{\mathrm{N}} * \mathrm{~A}_{\mathrm{N}}$ mechanism, ${ }^{21}$ the $\mathrm{N} 7$ protonated $\mathrm{dG}$ leads to generation of an oxacarbenium ion intermediate in the first step, ${ }^{41,43,44}$ with a Gibbs free energy barrier of $19 \mathrm{kcal} \mathrm{mol}^{-1.19}$ In the second step, nucleophilic attack by the water molecule on the oxacarbenium ion to yield the final products is considered a nearly barrierless process. ${ }^{19}$ For the cPDNs, previous DFT calculations show a large negative enthalpy for the $N$-glycosidic bond cleavage reactions of the protonated form. ${ }^{45}$ Our calculations of the hydrolysis of this set of nucleosides, based on DFT with the B3LYP ${ }^{26}$ functional and basis set $6-31++\mathrm{G}(\mathrm{d}, \mathrm{p})$, accurately predicted the trend observed experimentally. We also found exceptionally high stability of the $N$-glycosidic bond of 8-Oxo-dG in acid, which was attributed to its inability to protonate the base.

What happens after the cleavage of the $C 1^{\prime}-\mathrm{N} 9$ bond? For abasic sites, after the water addition the mixture of cyclic hemiacetals is the predominant form and the acyclic aldehyde form was estimated to be less than $1 \% .{ }^{46,47}$ But, to our knowledge, there are no reports on the type of products formed from ring-opened furanose sugars with a purine attached to it. To examine the products formed after the cleavage of $\mathrm{Cl}^{\prime}$-N9 bond, we first analyzed the products generated from 2-deoxyribose under acid conditions used in the $S$-cdG hydrolysis. From the sugar, only $\alpha$ and $\beta$ anomers of deoxyribopyranose and deoxyribopyranose oligomers were detected. With formic acid hydrolyzed $S$-cdG, a and $\beta$ deoxyribopyranose linked guanine were the major products. However, instead of the oligomeric products found in the reaction mixture of 2-deoxyribose, $S$-cdG gave a fraction of the two anomers of deoxyribofuranose linked guanine and other cyclic products (Scheme 4). As noted by others, ${ }^{47}$ the ring-opened aldehyde form was nearly undetectable. Oligomeric products were not detected in ddcdG hydrolysis as well. We believe that the steric effect of guanine at the $5^{\prime}$ position of the sugar prevented oligomerization in $S$-cdG and ddcdG. But for all of these molecules, six-membered deoxyribopyranoses were the major products.

\section{Biological implications}

Base excision repair proteins can accelerate the hydrolysis of the $\mathrm{N}$-glycosidic bond in the range $10^{7}-10^{12}$-fold. ${ }^{40}$ Although a variety of mechanisms are known to operate, a prevalent mechanism employs a water molecule to attack the anomeric carbon $\left(\mathrm{Cl}^{\prime}\right)$ of the nucleotide. For the cPDNs, no DNA glycosylase activity was detected in mammalian cellular extracts, ${ }^{6,7}$ but NEIL1 was suspected to be involved in the repair of cdA. ${ }^{8}$ In a more recent in vitro work, it was found that seven repair proteins, including NEIL1, which repair oxidative DNA damages, do not directly interact with $S$-cdG or $S$-cdA. ${ }^{48}$

Increased $\mathrm{N}$-glycosidic bond stability of $S$-cdG compared to dG excludes the possibility of spontaneous depurination of this lesion from DNA. Since base excision repair proteins cannot repair this damage, NER remains the only mechanism for its removal from DNA. It 
is therefore conceivable that in NER compromised cells, this highly mutagenic lesion may persist for a long time to exert its deleterious effects.

\section{Supplementary Material}

Refer to Web version on PubMed Central for supplementary material.

\section{Acknowledgments}

Funding Support

This work was supported by the National Institute of Environmental Health Sciences, NIH (grant ES013324). Upgrade of the $400 \mathrm{MHz}$ NMR at the University of Connecticut Chemistry Department was supported by NSF through the NSF-CRIF program.

\section{List of abbreviations}

cPDN

$S$-cdG and $R$-cdG

$S$-cdA and $R$-cdA

ddedG

8-Oxo-dG

8-Me-dG

2-deoxyribose

NER

HSQC

HMBC $8,5^{\prime}$-cyclopurine $2^{\prime}$-deoxynucleoside

$\left(5^{\prime} S\right)$ - and $\left(5^{\prime} R\right)-8,5^{\prime}$-cyclo- $2^{\prime}$-deoxyguanosine, respectively $\left(5^{\prime} S\right)$ - and $\left(5^{\prime} R\right)-8,5^{\prime}$-cyclo- $2^{\prime}$-deoxyadenosine, respectively $8,5^{\prime}$-cyclo- $2^{\prime}, 5^{\prime}$-dideoxyguanosine 7,8-dihydro-8-oxo-2' -deoxyguanosine 8 -methyl-2' -deoxyguanosine 2-deoxy-D-erythro-pentose nucleotide excision repair heteronuclear single quantum coherence heteronuclear multiple bond correlation

\section{References}

1. Chatgilialoglu C, Ferreri C, Terzidis MA. Purine 5',8-cyclonucleoside lesions: chemistry and biology. Chem Soc Rev. 2011; 40:1368-1382. [PubMed: 21221459]

2. Jaruga P, Dizdaroglu M. 8,5'-Cyclopurine-2' ${ }^{\prime}$-deoxynucleosides in DNA: mechanisms of formation, measurement, repair and biological effects. DNA Repair (Amst). 2008; 7:1413-1425. [PubMed: 18603018]

3. Jaruga P, Xiao Y, Nelson BC, Dizdaroglu M. Measurement of ( $\left.5^{\prime} \mathrm{R}\right)$ - and ( $\left.5^{\prime} \mathrm{S}\right)-8,5^{\prime}$-cyclo- $2^{\prime}$ deoxyadenosines in DNA in vivo by liquid chromatography/isotope-dilution tandem mass spectrometry. Biochem Biophys Res Commun. 2009; 386:656-660. [PubMed: 19559005]

4. Dizdaroglu M, Jaruga P, Rodriguez H. Identification and quantification of 8,5' -cyclo- $2^{\prime}$-deoxyadenosine in DNA by liquid chromatography/ mass spectrometry. Free Radic Biol Med. 2001; 30:774-784. [PubMed: 11275477]

5. Keck K. Formation of cyclonucleotides during irradiation of aqueous solutions of purine nucleotides. Z Naturforsch B. 1968; 23:1034-1043. [PubMed: 4387605]

6. Kuraoka I, Bender C, Romieu A, Cadet J, Wood RD, Lindahl T. Removal of oxygen free-radicalinduced $5^{\prime}, 8$-purine cyclodeoxynucleosides from DNA by the nucleotide excision-repair pathway in human cells. Proc Natl Acad Sci U S A. 2000; 97:3832-3837. [PubMed: 10759556]

7. Brooks PJ, Wise DS, Berry DA, Kosmoski JV, Smerdon MJ, Somers RL, Mackie H, Spoonde AY, Ackerman EJ, Coleman K, Tarone RE, Robbins JH. The oxidative DNA lesion 8,5' $-(\mathrm{S})$-cyclo- $2^{\prime}$ deoxyadenosine is repaired by the nucleotide excision repair pathway and blocks gene expression in mammalian cells. J Biol Chem. 2000; 275:22355-22362. [PubMed: 10801836] 
8. Jaruga P, Xiao Y, Vartanian V, Lloyd RS, Dizdaroglu M. Evidence for the involvement of DNA repair enzyme NEIL1 in nucleotide excision repair of $\left(5^{\prime} \mathrm{R}\right)$ - and $\left(5^{\prime} \mathrm{S}\right)-8,5^{\prime}$-cyclo- $2^{\prime}$ deoxyadenosines. Biochemistry. 2010; 49:1053-1055. [PubMed: 20067321]

9. Brooks PJ. The 8,5'-cyclopurine- $2^{\prime}$-deoxynucleosides: candidate neurodegenerative DNA lesions in xeroderma pigmentosum, and unique probes of transcription and nucleotide excision repair. DNA Repair (Amst). 2008; 7:1168-1179. [PubMed: 18495558]

10. Kirkali G, de Souza-Pinto NC, Jaruga P, Bohr VA, Dizdaroglu M. Accumulation of (5'S)-8,5' cyclo- $2^{\prime}$-deoxyadenosine in organs of Cockayne syndrome complementation group B gene knockout mice. DNA Repair (Amst). 2009; 8:274-278. [PubMed: 18992371]

11. Marietta C, Gulam H, Brooks PJ. A single 8, $5^{\prime}$-cyclo- $2^{\prime}$-deoxyadenosine lesion in a TATA box prevents binding of the TATA binding protein and strongly reduces transcription in vivo. DNA Repair (Amst). 2002; 1:967-975. [PubMed: 12531024]

12. Kuraoka I, Robins P, Masutani C, Hanaoka F, Gasparutto D, Cadet J, Wood RD, Lindahl T. Oxygen free radical damage to DNA. Translesion synthesis by human DNA polymerase eta and resistance to exonuclease action at cyclopurine deoxynucleoside residues. J Biol Chem. 2001; 276:49283-49288. [PubMed: 11677235]

13. Jasti VP, Das RS, Hilton BA, Weerasooriya S, Zou Y, Basu AK. (5'S)-8,5' -cyclo-2' deoxyguanosine is a strong block to replication, a potent pol $\mathrm{V}$-dependent mutagenic lesion, and is inefficiently repaired in Escherichia coli. Biochemistry. 2011; 50:3862-3865. [PubMed: 21491964]

14. Yuan B, Wang J, Cao H, Sun R, Wang Y. High-throughput analysis of the mutagenic and cytotoxic properties of DNA lesions by next-generation sequencing. Nucleic Acids Res. 2011; 39:5945-5954. [PubMed: 21470959]

15. Huang H, Das RS, Basu AK, Stone MP. Structure of ( $\left.5^{\prime} \mathrm{S}\right)-8,5^{\prime}$-cyclo- $2^{\prime}$-deoxyguanosine in DNA. J Am Chem Soc. 2011; 133:20357-20368. [PubMed: 22103478]

16. Huang H, Das RS, Basu AK, Stone MP. Structures of ( $\left.5^{\prime} \mathrm{S}\right)-8,5^{\prime}$-Cyclo-2' -deoxyguanosine Mismatched with dA or dT. Chem Res Toxicol. 2012; 25:478-490. [PubMed: 22309170]

17. Pullman A, Pullman B. Molecular electrostatic potential of the nucleic acids. Q Rev Biophys. 1981; 14:289-380. [PubMed: 7027300]

18. Suzuki T, Ohsumi S, Makino K. Mechanistic studies on depurination and apurinic site chain breakage in oligodeoxyribonucleotides. Nucleic Acids Res. 1994; 22:4997-5003. [PubMed: 7800492]

19. Rios-Font R, Rodriguez-Santiago L, Bertran J, Sodupe M. Influence of N7 protonation on the mechanism of the $\mathrm{N}$-glycosidic bond hydrolysis in 2 '-deoxyguanosine. A theoretical study. J Phys Chem B. 2007; 111:6071-6077. [PubMed: 17477565]

20. Przybylski JL, Wetmore SD. Modeling the dissociative hydrolysis of the natural DNA nucleosides. J Phys Chem B. 2010; 114:1104-1113. [PubMed: 20039632]

21. Guthrie RD, Jencks WP. Iupac Recommendations for the Representation of Reaction-Mechanisms. Accounts Chem Res. 1989; 22:343-349.

22. Theruvathu JA, Jaruga P, Dizdaroglu M, Brooks PJ. The oxidatively induced DNA lesions 8,5' cyclo- $2^{\prime}$-deoxyadenosine and 8 -hydroxy-2 $2^{\prime}$-deoxyadenosine are strongly resistant to acid-induced hydrolysis of the glycosidic bond. Mech Ageing Dev. 2007; 128:494-502. [PubMed: 17692895]

23. Romieu A, Gasparutto D, Cadet J. Synthesis and characterization of oligonucleotides containing $5^{\prime}, 8$-cyclopurine $2^{\prime}$-deoxyribonucleosides: ( $\left.5^{\prime} \mathrm{R}\right)-5^{\prime}, 8$-cyclo- $2^{\prime}$-deoxyadenosine, $\left(5^{\prime} \mathrm{S}\right)-5^{\prime}, 8$ cyclo-2' $2^{\prime}$ deoxyguanosine, and $\left(5^{\prime} \mathrm{R}\right)-5^{\prime}, 8$-cyclo-2' ${ }^{\prime}$-deoxyguanosine. Chem Res Toxicol. 1999; 12:412-421. [PubMed: 10328751]

24. Kohda K, Tsunomoto H, Minoura Y, Tanabe K, Shibutani S. Synthesis, miscoding specificity, and thermodynamic stability of oligodeoxynucleotide containing 8-methyl-2' ${ }^{\prime}$-deoxyguanosine. Chem Res Toxicol. 1996; 9:1278-1284. [PubMed: 8951229]

25. RA; Frisch, MJ.; Trucks, GW.; Schlegel, HB.; Scuseria, GE.; Robb, MA.; Cheeseman, JR.; Scalmani, G.; Barone, V.; Mennucci, B.; Petersson, GA.; Nakatsuji, H.; Caricato, M.; Li, X.; Hratchian, HP.; Izmaylov, AF.; Bloino, J.; Zheng, G.; Sonnenberg, JL.; Hada, M.; Ehara, M.; Toyota, K.; Fukuda, R.; Hasegawa, J.; Ishida, M.; Nakajima, T.; Honda, Y.; Kitao, O.; Nakai, H.; Vreven, T.; Montgomery, JA., Jr; Peralta, JE.; Ogliaro, F.; Bearpark, M.; Heyd, JJ.; Brothers, E.; 
Kudin, KN.; Staroverov, VN.; Kobayashi, R.; Normand, J.; Raghavachari, K.; Rendell, A.; Burant, JC.; Iyengar, SS.; Tomasi, J.; Cossi, M.; Rega, N.; Millam, JM.; Klene, M.; Knox, JE.; Cross, JB.; Bakken, V.; Adamo, C.; Jaramillo, J.; Gomperts, R.; Stratmann, RE.; Yazyev, O.; Austin, AJ.; Cammi, R.; Pomelli, C.; Ochterski, JW.; Martin, RL.; Morokuma, K.; Zakrzewski, VG.; Voth, GA.; Salvador, P.; Dannenberg, JJ.; Dapprich, S.; Daniels, AD.; Farkas, Ö.; Foresman, JB.; Ortiz, JV.; Cioslowski, J.; Fox, DJ. Gaussian 09. 2009.

26. Becke AD. Density-Functional Thermochemistry. 3 The Role of Exact Exchange. J Chem Phys. 1993; 98:5648-5652.

27. Lee CT, Yang WT, Parr RG. Development of the Colle-Salvetti Correlation-Energy Formula into a Functional of the Electron-Density. Phys Rev B. 1988; 37:785-789.

28. Cossi M, Barone V, Cammi R, Tomasi J. Ab initio study of solvated molecules: A new implementation of the polarizable continuum model. Chem Phys Lett. 1996; 255:327-335.

29. Peng CY, Schlegel HB. Combining Synchronous Transit and Quasi-Newton Methods to Find Transition-States. Israel J Chem. 1993; 33:449-454.

30. Jaguar, v. Schrödinger, LLC; New York, NY: 2011.

31. Schindler M. Magnetic-Properties in Terms of Localized Quantities. 9 The DNA Bases and the Protonation of Adenine. J Am Chem Soc. 1988; 110:6623-6630.

32. Seckarova P, Marek R, Malinakova K, Kolehmainen E, Hockova D, Hocek M, Sklenar V. Direct determination of tautomerism in purine derivatives by low-temperature NMR spectroscopy. Tetrahedron Lett. 2004; 45:6259-6263.

33. Zheng Y, Xue Y, Yan SG. The effects of oxidation and protonation on the N-glycosidic bond stability of 8-oxo-2 '-deoxyguanosine: DFT study. J Mol Struc-Theochem. 2008; 860:52-57.

34. Greisch JF, Leyh B, De Pauw E. Collision induced dissociation of deuterium enriched protonated $2^{\prime}$-deoxyguanosine. Eur Phys J D. 2009; 51:89-96.

35. Lipscomb LA, Peek ME, Morningstar ML, Verghis SM, Miller EM, Rich A, Essigmann JM, Williams LD. X-ray structure of a DNA decamer containing 7,8-dihydro-8-oxoguanine. Proc Natl Acad Sci U S A. 1995; 92:719-723. [PubMed: 7846041]

36. Xu Y, Ikeda R, Sugiyama H. 8-Methylguanosine: a powerful Z-DNA stabilizer. J Am Chem Soc. 2003; 125:13519-13524. [PubMed: 14583048]

37. Jang YH, Goddard WA 3rd, Noyes KT, Sowers LC, Hwang S, Chung DS. First principles calculations of the tautomers and $\mathrm{pK}(\mathrm{a})$ values of 8-oxoguanine: implications for mutagenicity and repair. Chem Res Toxicol. 2002; 15:1023-1035. [PubMed: 12184786]

38. Gorenstein DG. Stereoelectronic Effects in Biomolecules. Chem Rev. 1987; 87:1047-1077.

39. Haromy TP, Raleigh J, Sundaralingam M. Enzyme-bound conformations of nucleotide substrates. X-ray structure and absolute configuration of 8,5' -cycloadenosine monohydrate. Biochemistry. 1980; 19:1718-1722. [PubMed: 7378372]

40. Stivers JT, Jiang YL. A mechanistic perspective on the chemistry of DNA repair glycosylases. Chem Rev. 2003; 103:2729-2759. [PubMed: 12848584]

41. Zoltewicz JA, Clark DF, Sharpless TW, Grahe G. Kinetics and mechanism of the acid-catalyzed hydrolysis of some purine nucleosides. J Am Chem Soc. 1970; 92:1741-1749. [PubMed: 5418456]

42. Baik MH, Friesner RA, Lippard SJ. Theoretical study on the stability of N-glycosyl bonds: why does N7-platination not promote depurination? J Am Chem Soc. 2002; 124:4495-4503. [PubMed: 11960480]

43. Hevesi L, Wolfson-Davidson E, Nagy JB, Nagy OB, Bruylants A. Contribution to the mechanism of the acid-catalyzed hydrolysis of purine nucleosides. J Am Chem Soc. 1972; 94:4715-4720. [PubMed: 5036169]

44. Kampf G, Kapinos LE, Griesser R, Lippert B, Sigel H. Comparison of the acid-base properties of purine derivatives in aqueous solution. Determination of intrinsic proton affinities of various basic sites. J Chem Soc Perk T. 2002; 2:1320-1327.

45. Karwowski BT. The difference in stability between $5^{\prime} \mathrm{R}$ and $5^{\prime} \mathrm{S}$ diastereomers of 5 ',8cyclopurine- 2 -deoxynucleosides. DFT study in gaseous and aqueous phase. Cent Eur J Chem. 2010; 8:134-141. 
46. Wilde JA, Bolton PH, Mazumder A, Manoharan M, Gerlt JA. Characterization of the equilibrating forms of the aldehydic abasic site in duplex DNA by 17O-NMR. J Am Chem Soc. 1989; 111:1894-1896.

47. Pierce J, Serianni AS, Barker R. Anomerization of Furanose Sugars and Sugar Phosphates. J Am Chem Soc. 1985; 107:2448-2456.

48. Pande P, Das RS, Sheppard C, Kow YW, Basu AK. Repair efficiency of ( $5^{\prime}$ S)-8, $5^{\prime}$-cyclo- $2^{\prime}$ deoxyguanosine and $\left(5^{\prime} \mathrm{S}\right)-8,5^{\prime}$-cyclo- $2^{\prime}$-deoxyadenosine depends on the complementary base. DNA Repair (Amst). 2012:11. (in press). 


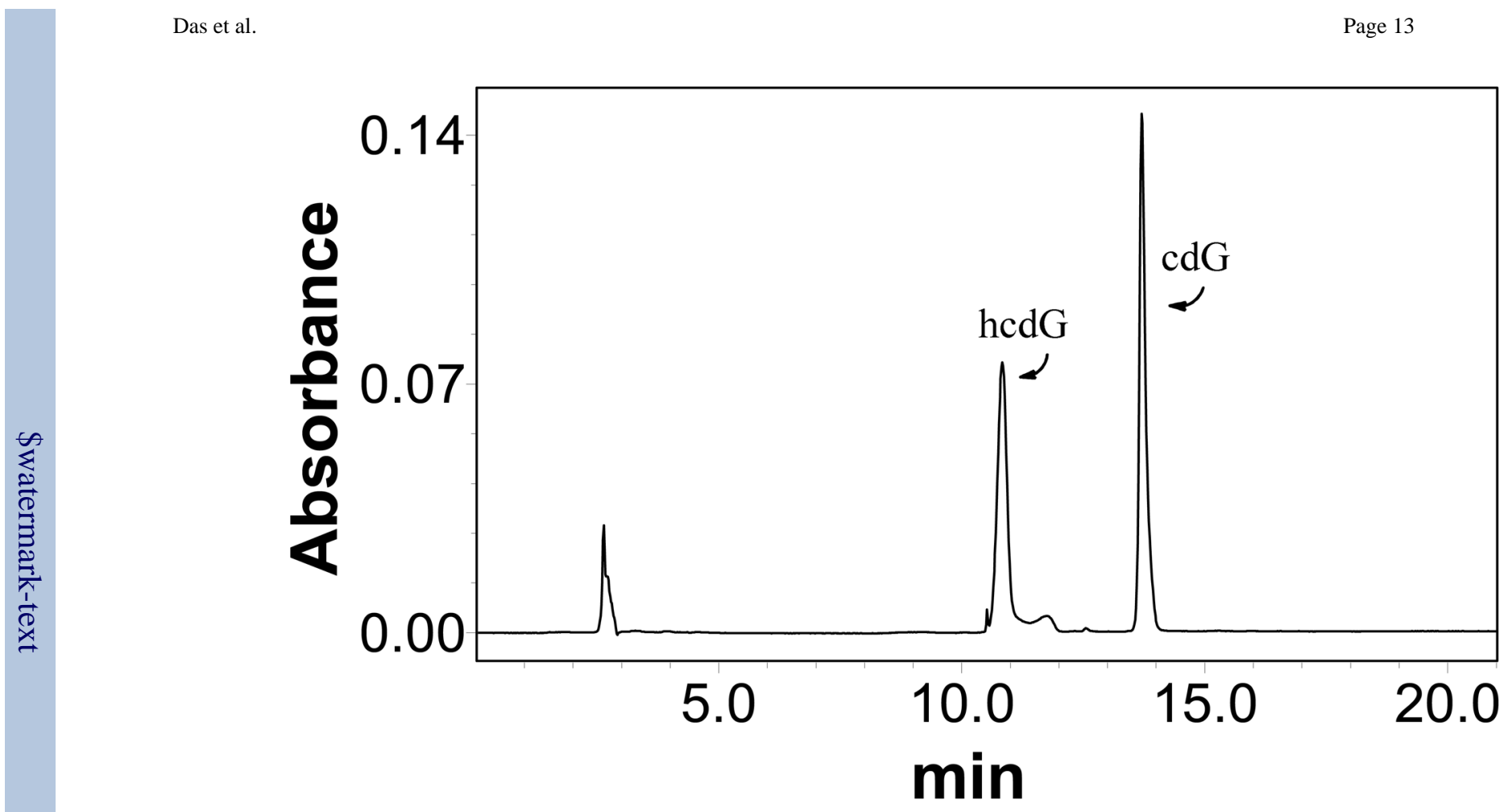

Figure 1.

Reverse-phase HPLC profile of $S$-cdG following incubation with $10 \%$ formic acid at $37{ }^{\circ} \mathrm{C}$ for $7 \mathrm{~h}$. 


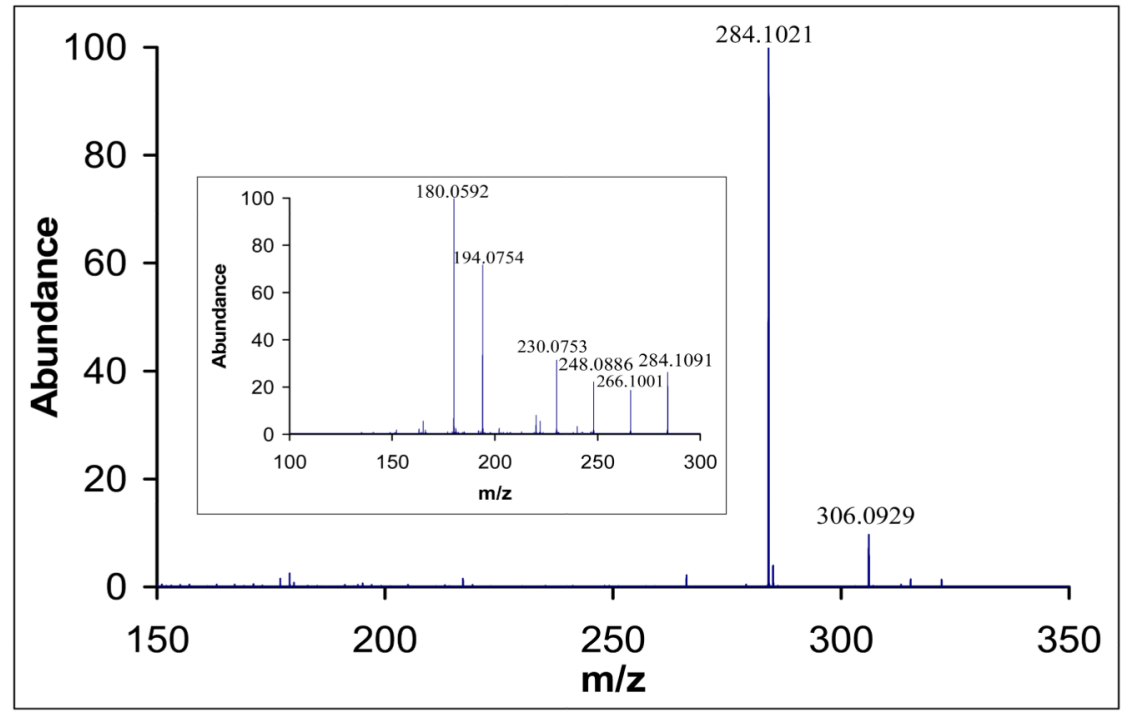

Figure 2.

Mass spectrometry analysis of hcdG. MS-MS of 284.1 peak is shown in the inset. 


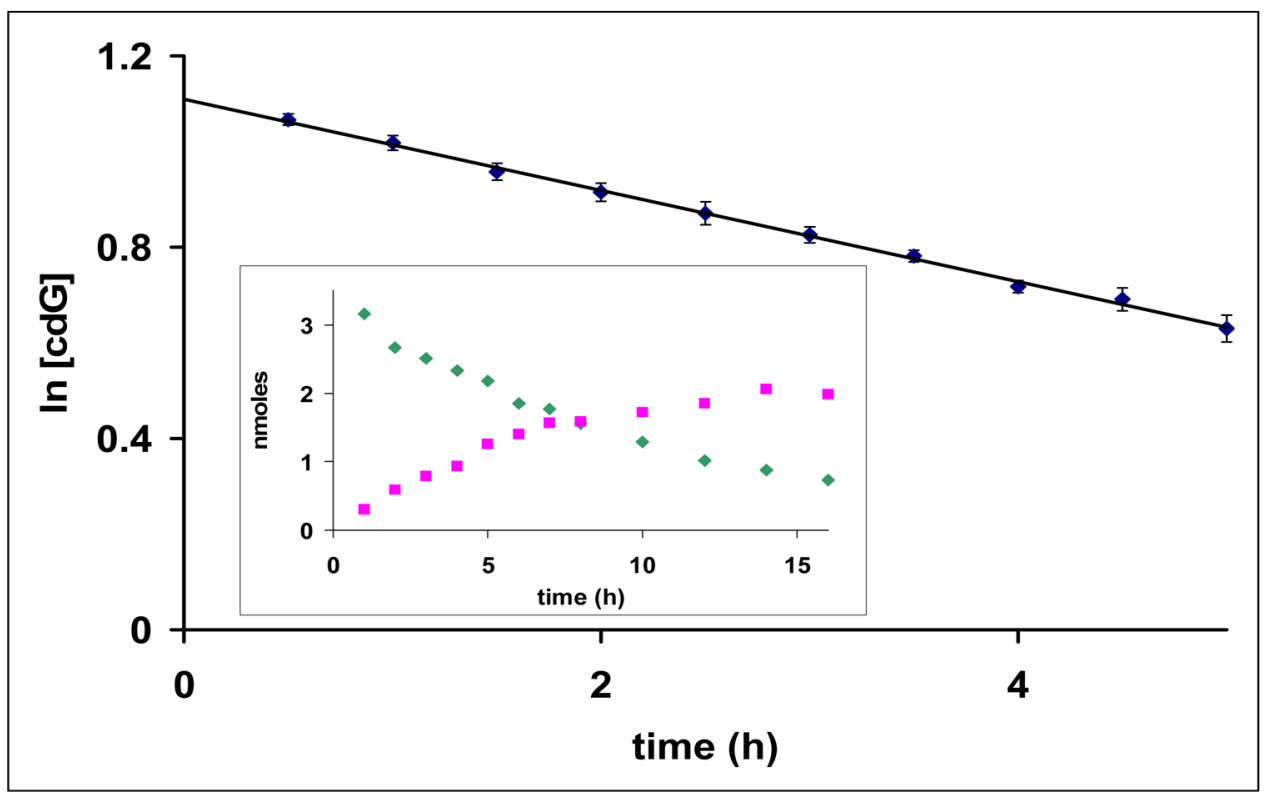

Figure 3.

Kinetics of $\mathrm{N}$-glycosidic bond cleavage of $S$-cdG in $10 \%$ formic acid at $37{ }^{\circ} \mathrm{C}$ monitored by HPLC. The inset shows the disappearance of $S$-cdG peak (green diamonds) and appearance of hcdG peak (pink squares) with time. 


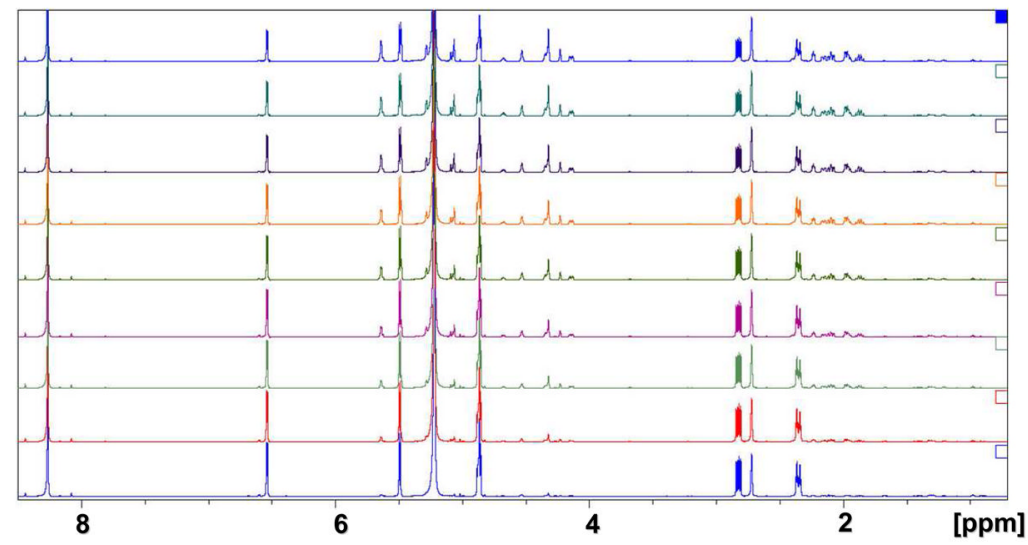

Figure 4.

${ }^{1} \mathrm{H}-\mathrm{NMR}$ time course analysis (shown here for the first two hours) (calibrated with formic acid peak at $8.26 \mathrm{ppm}$ ) of $S$-cdG in $10 \%$ DMSO- $d_{6}, 20 \%$ DCOOD and $70 \% \mathrm{D}_{2} \mathrm{O}$ at $37{ }^{\circ} \mathrm{C}$. The H-1 ${ }^{\prime}$ peak (moved downfield to $6.52 \mathrm{ppm}$ ) was integrated to measure the loss of $S$-cdG. Starting from the bottom panel at zero time, spectra were taken every $15 \mathrm{~min}$. 


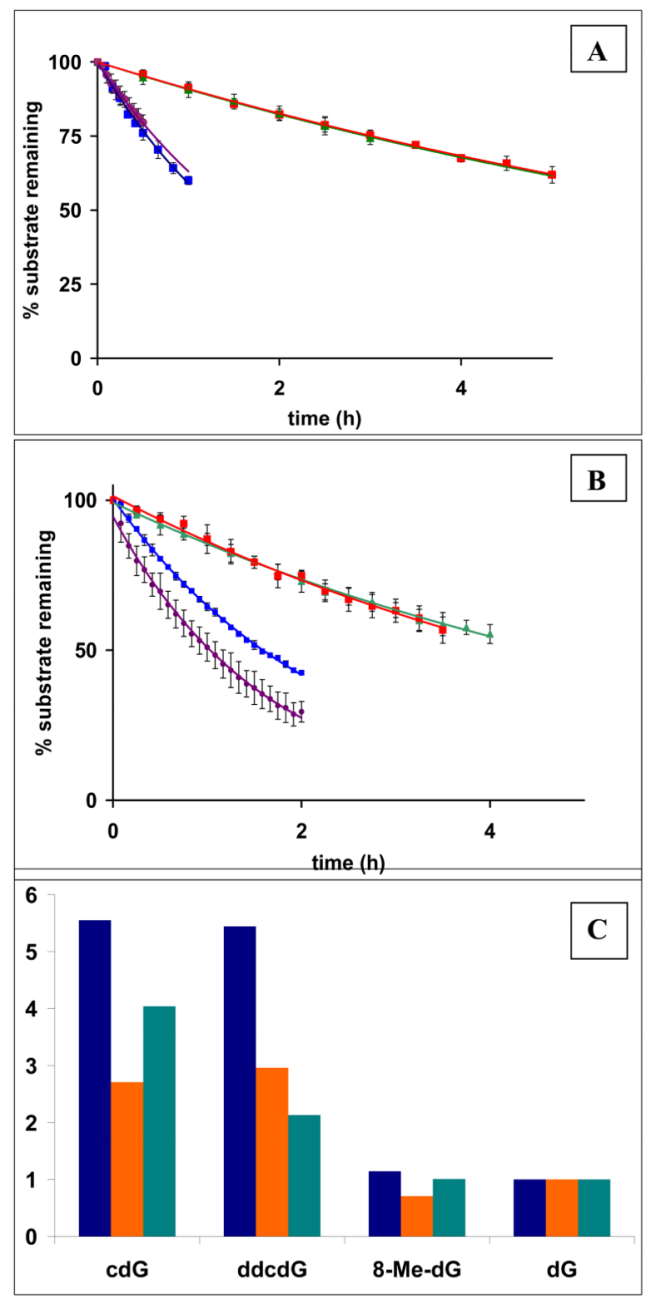

Figure 5.

Comparison of the kinetics of $N$-glycosidic bond cleavage of $S$-cdG (red filled squares), ddcdG (green filled triangles), 8-Me-dG (purple filled circles), and dG (blue filled squares) in (A) $10 \%$ formic acid at $37^{\circ} \mathrm{C}$ monitored by HPLC and (B) $20 \%$ DCOOD, $10 \%$ DMSO$d_{6}$, and $70 \% \mathrm{D}_{2} \mathrm{O}$ at $37{ }^{\circ} \mathrm{C}$ monitored by ${ }^{1} \mathrm{H}-\mathrm{NMR}$ of the $\mathrm{H}-1^{\prime}$ peak. Each point represents at least three independent determinations. Their half-lives calculated from panel A (dark blue) and panel $\mathbf{B}$ (orange) and normalized to that of $\mathrm{dG}$ are shown in panel $\mathbf{C}$. The half-lives determined by the computational study (Table 2) are also shown here in dark green. 


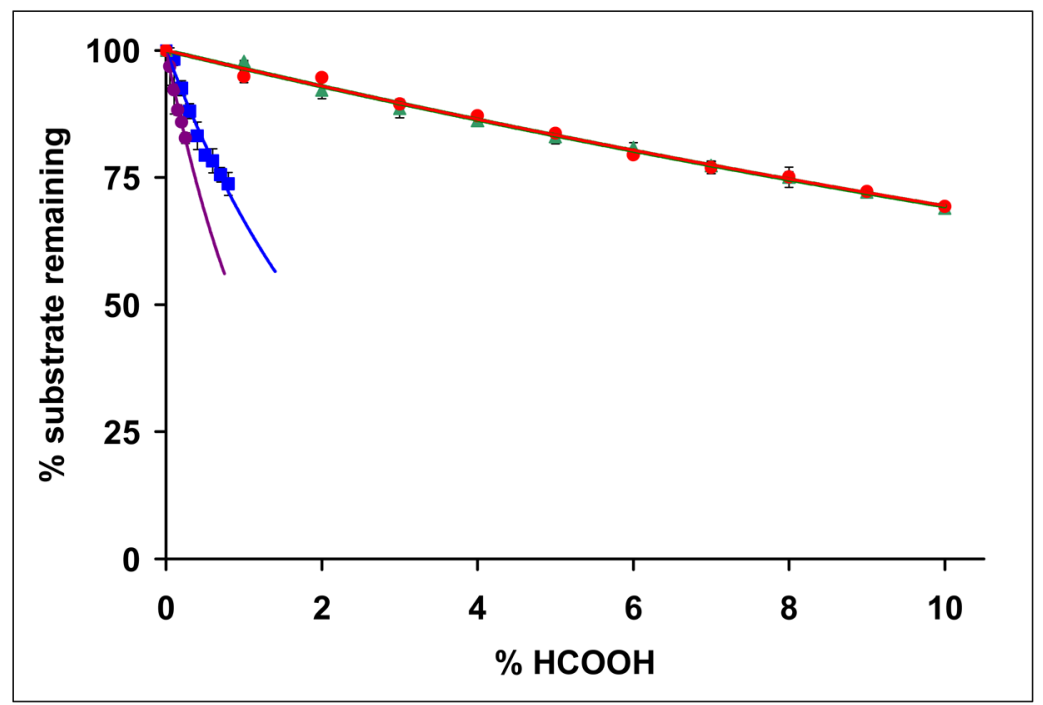

Figure 6.

HPLC monitoring of $N$-glycosidic bond cleavage of $S$-cdG (red filled squares), ddcdG (green filled triangles), Me-dG (purple filled circles), and $\mathrm{dG}$ (blue filled squares) after $4 \mathrm{~h}$ treatment at $37^{\circ} \mathrm{C}$ with increasing concentration of formic acid. 

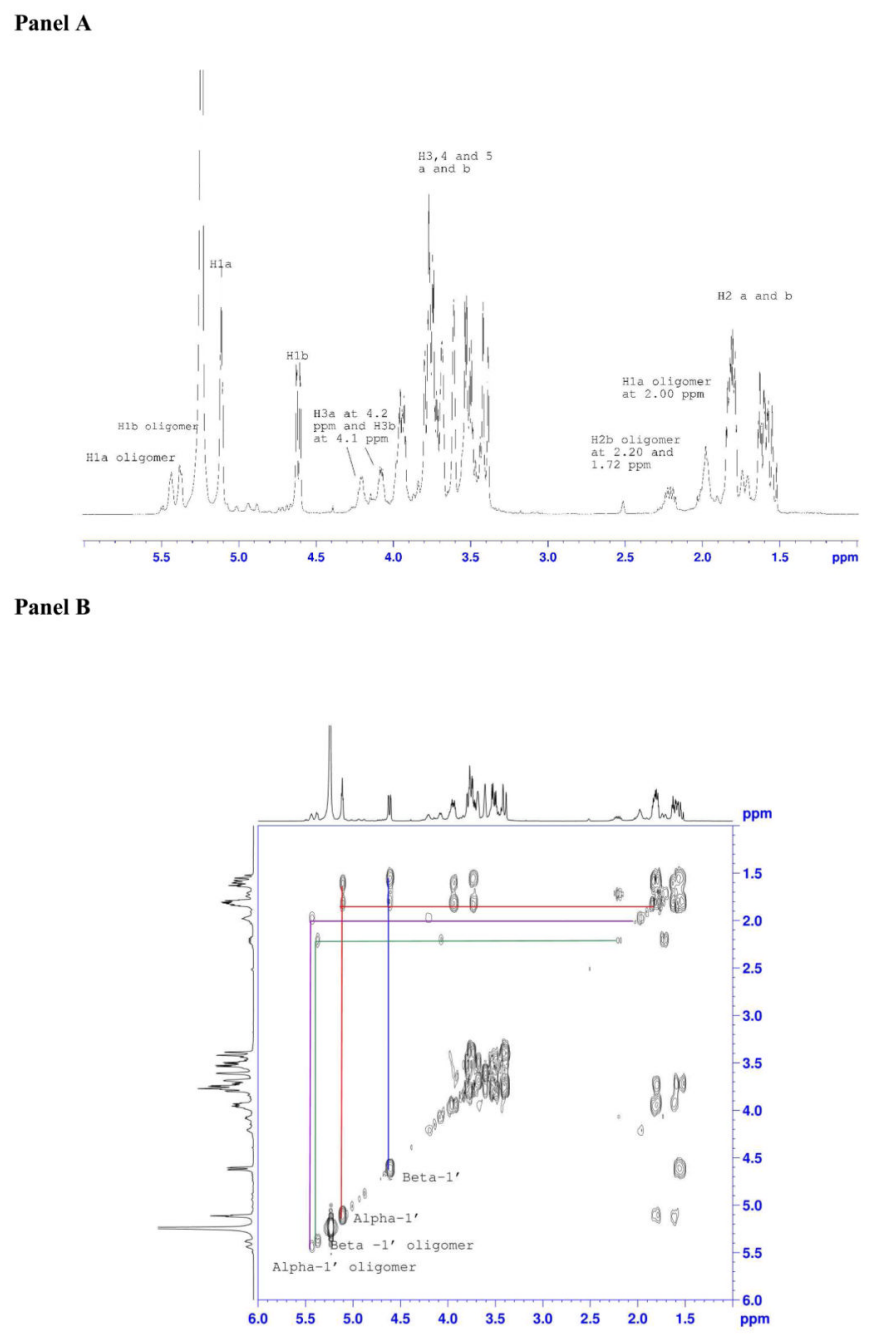

Figure 7.

Panel A ${ }^{1} \mathrm{H}$-NMR spectrum of 2-deoxyribose following acid hydrolysis in $20 \%$ deuterated formic acid.

Panel B. COSY spectrum of the same, which leads to four products: $a$ and $\beta$ deoxyribopyranose (red and blue line, respectively), and oligomerized $\alpha$ and $\beta$ deoxyribopyranose (purple and green line, respectively). 
Panel A

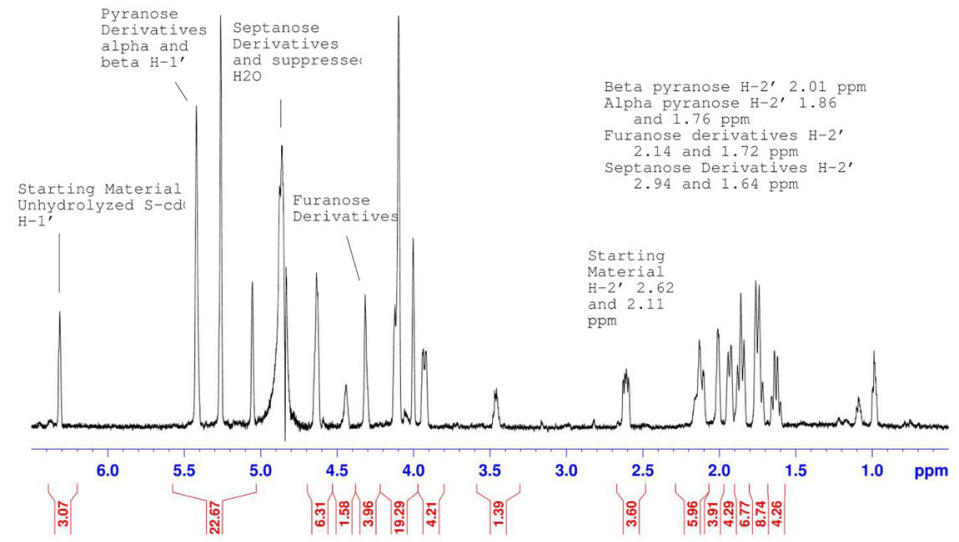

Panel B

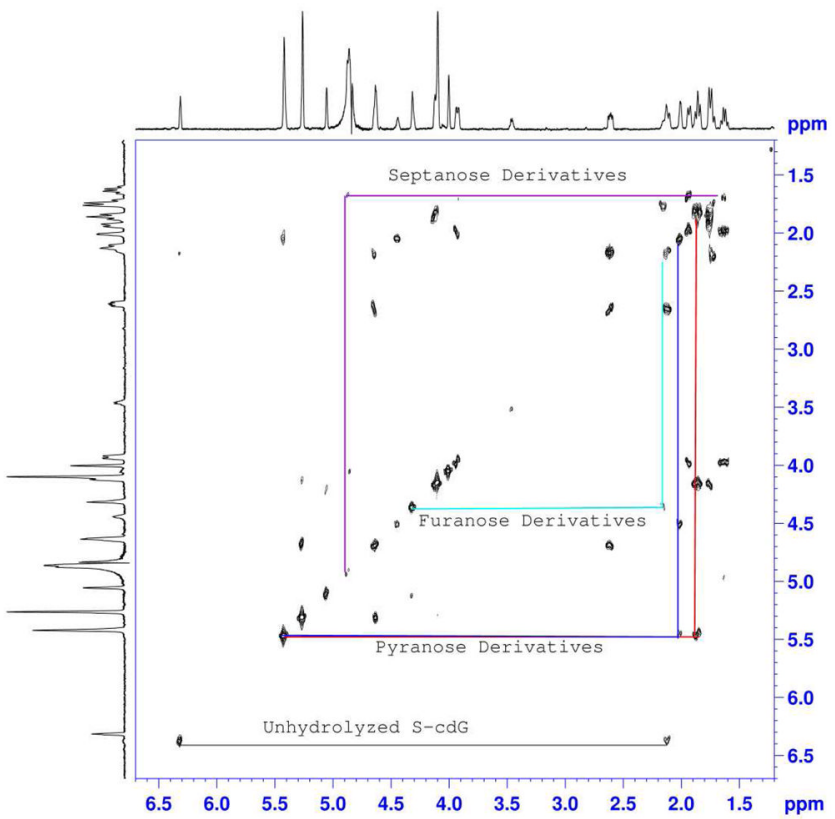

Figure 8.

Panel $\mathrm{A}^{1} \mathrm{H}-\mathrm{NMR}$ spectrum of $S$-cdG following acid hydrolysis in $20 \%$ deuterated formic acid.

Panel B. COSY spectrum of the same, which leads to four products: $\alpha$ and $\beta$ deoxyribopyranose (red and blue line), $\alpha$ and $\beta$ deoxyribofuranose (green line), suspected septanose (fuchsia line), unhydrolyzed $S$-cdG (black line). 

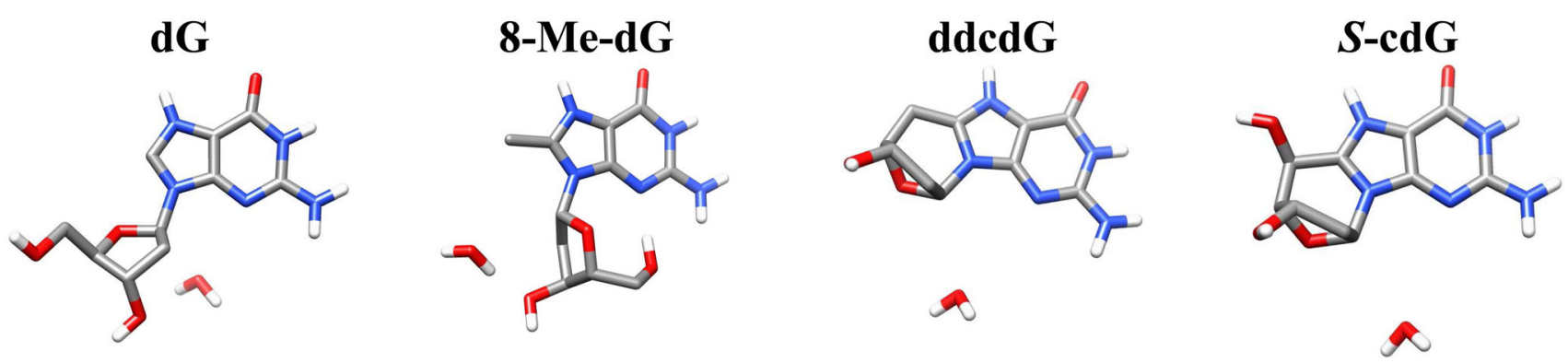

Figure 9.

Computed minimum energy structures of dG (anti), 8-Me-dG (syn), ddcdG (anti), and $S$ cdG (anti) with a reactive water molecule. 


$$
\mathrm{Nu}+\mathrm{H}^{+} \rightleftharpoons \mathrm{NuH}^{+} \frac{\mathrm{k}_{2}}{\mathrm{H}_{2} \mathrm{O}} \longrightarrow \mathrm{NuOH}+\mathrm{H}^{+}
$$

Scheme 1. 

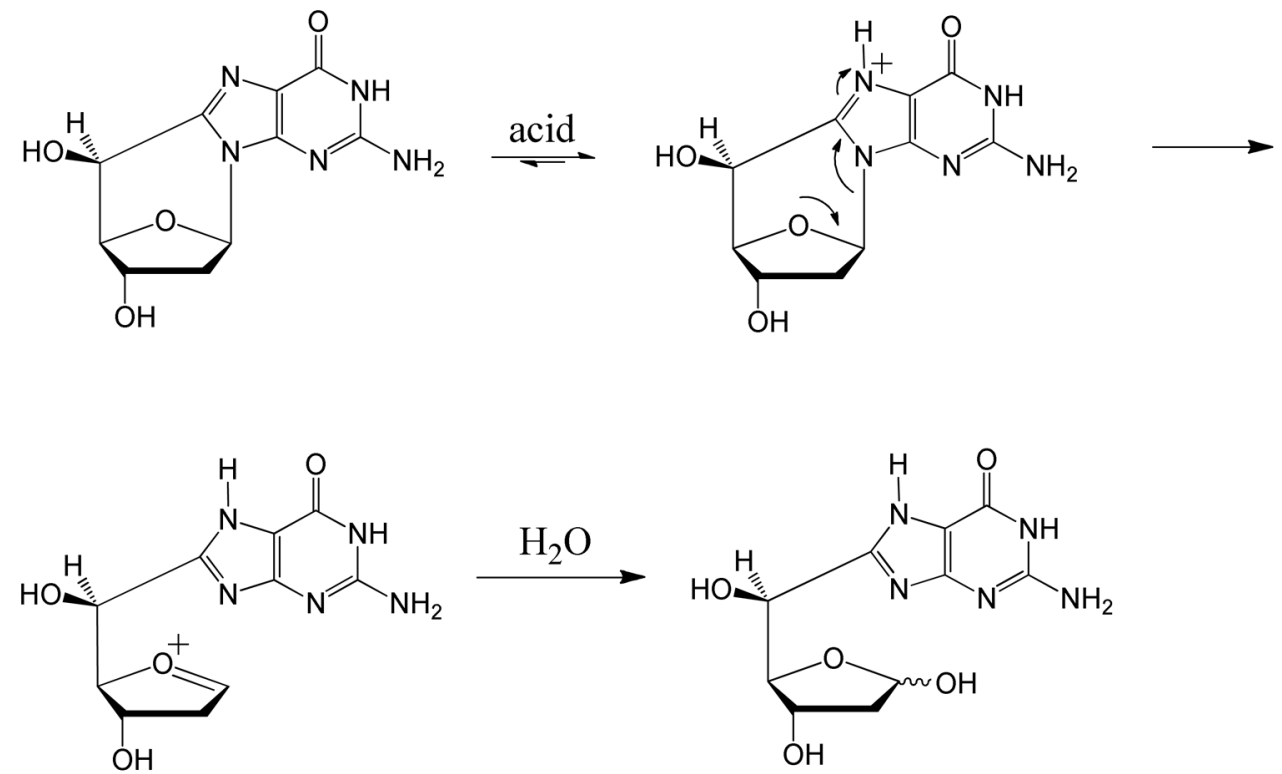

Scheme 2.

Postulated mechanism of acid-catalyzed $N$-glycosidic bond cleavage of $S$-cdG. 
Das et al.
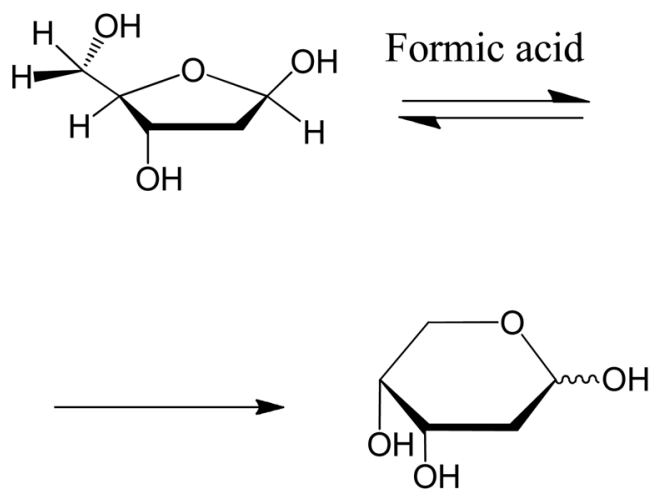

$\alpha 35 \% \& \beta 30 \%$
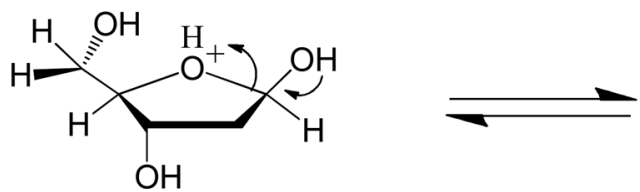

+ Deoxyribopyranose

Oligomers

$30 \%$ total

Scheme 3.

Postulated mechanism of formic acid-catalyzed reaction of 2-deoxyribose. 


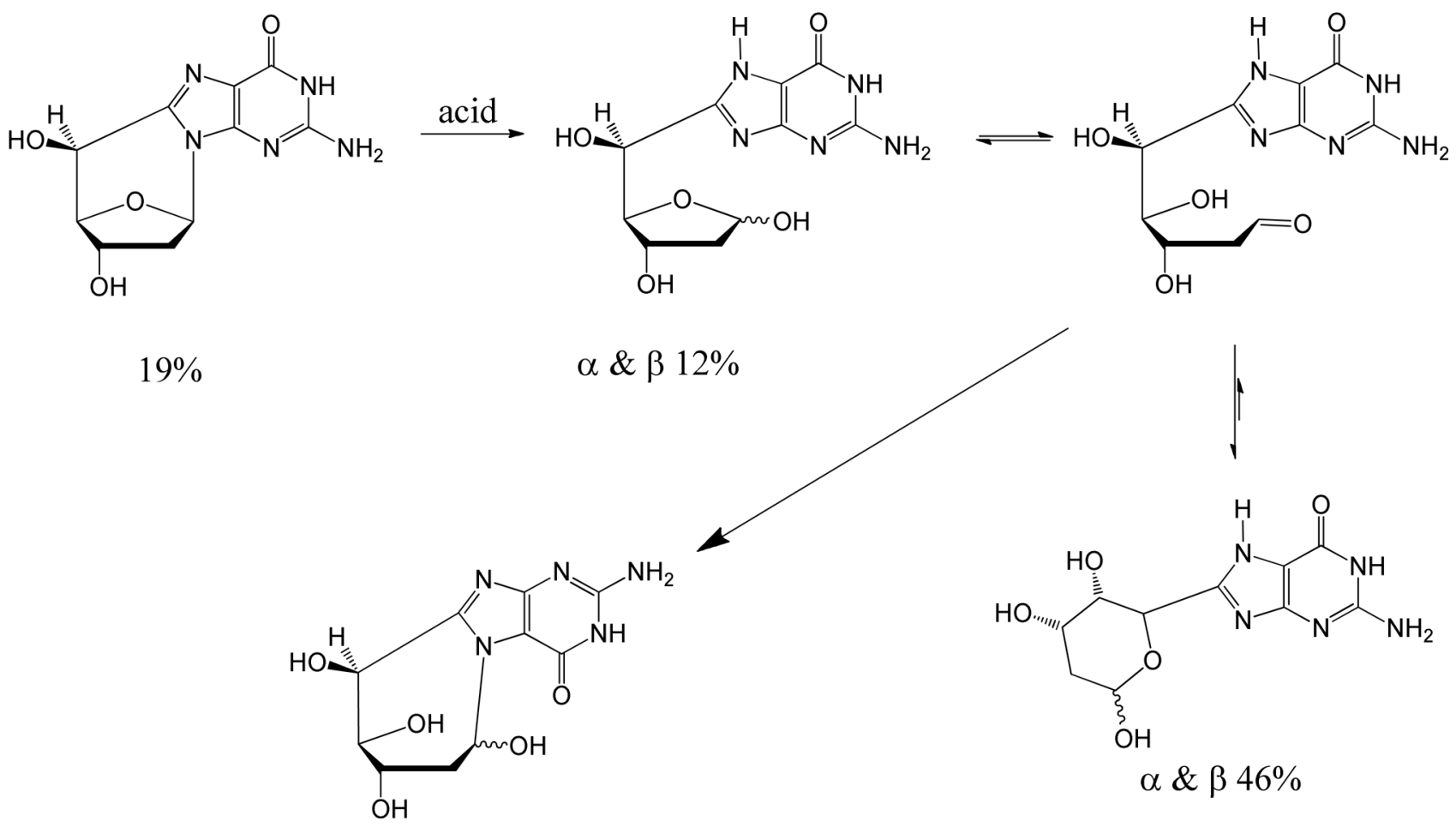

Scheme 4.

Formic acid-catalyzed ring-opening and rearrangement of $S$-cdG, according to NMR result. The postulated structure of a septanose derivative is shown. These and other unidentified products have been detected at $\sim 23 \%$. 


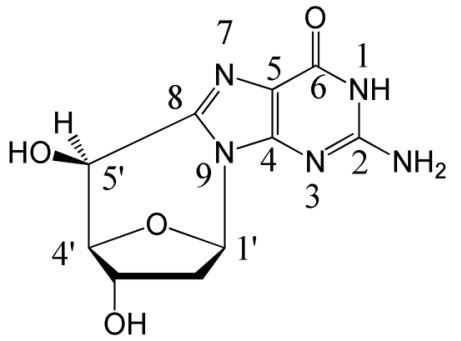

$S$-cdG<smiles>Cc1nc2c(=O)[nH]c(N)nc2n1[C@H]1C[C@@H](O)[C@@H](CO)O1</smiles>

8-Me-dG

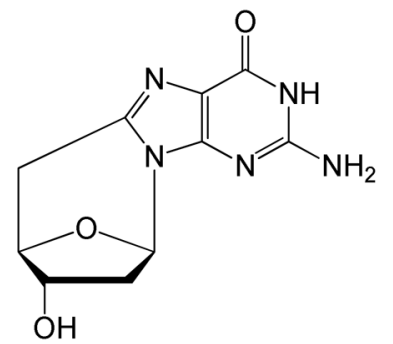

ddedG

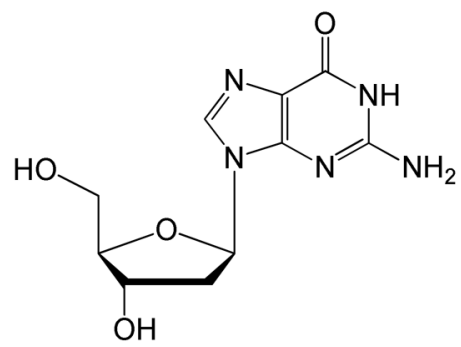

dG

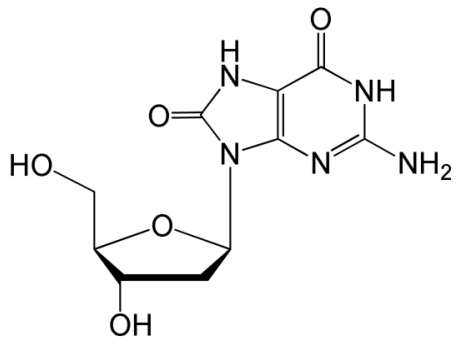

8-Oxo-dG

Chart 1.

Structures of the compounds used in this study for $N$-glycosidic bond cleavage: $S$-cdG, ddcdG, 8-Me-dG, 8-Oxo-dG, and dG. 


\section{Table 1}

Computed values of pKa at the N7 position, activation energies, and rate constants for step 2 in the reaction.

\begin{tabular}{c|l|l|c}
\hline Molecule & $\mathbf{p K}_{\mathbf{a}}$ & $\mathbf{k}_{\mathbf{2}}$ & Activation energy $\mathbf{~ k a l ~ \text { mol} ^ { \mathbf { 1 } }}$ \\
\hline $\mathrm{dG}$ & 3.2 & $98.2 \times 10^{-4}$ & 21.09 \\
8 -Me-dG & 3.5 & $37.7 \times 10^{-4}$ & 21.52 \\
$\mathrm{ddcdG}$ & 3.7 & $12.0 \times 10^{-4}$ & 22.27 \\
$S$-cdG & 2.7 & $65.9 \times 10^{-4}$ & 21.30 \\
\hline
\end{tabular}


Table 2

Ratio of the half-life of a nucleoside to that of $\mathrm{dG}$.

\begin{tabular}{|c|c|c|c|}
\hline Molecule & $\begin{array}{c}\text { Ratio (Experimentally, in 10\% } \mathrm{HCOOH} \\
\text { monitored by HPLC) }\end{array}$ & $\begin{array}{l}\text { Ratio (Experimentally, in } 20 \% \text { DCOOD, } 10 \% \\
\text { DMSO- } d_{6} \text { and } 70 \% \mathrm{D}_{2} \mathrm{O} \text { monitored by NMR) }\end{array}$ & Ratio (Theoretically) \\
\hline $\mathrm{dG}$ & 1.00 & 1.00 & 1.00 \\
\hline 8-Me-dG & 1.15 & 0.70 & 1.01 \\
\hline ddcdG & 5.44 & 2.96 & 2.13 \\
\hline$S$-cdG & 5.55 & 2.71 & 4.04 \\
\hline
\end{tabular}

